\title{
Demonstration of the $\mathrm{Rb}_{1}$ lipopolysaccharide core structure in Salmonella strains with the monoclonal antibody M105
}

\author{
LUCIELLE P. MANSFIELD and S.J. FORSYTHE \\ Department of Life Sciences, Nottingham Trent University, Clifton Lane, Nottingham NG11 8NS
}

\begin{abstract}
The lipopolysaccharide (LPS) from 42 strains representing 19 Salmonella serogroups was differentiated into characteristic ladder-like profiles by SDS-PAGE analysis. The core-specific antibody $M 105\left(R a, R b_{1}\right.$ and $\left.R b_{2}\right)$ was used in an immunoblot assay of SDS-PAGE-separated LPS molecules. The M105 antibody bound to the R-type LPS of 18 of the 20 Salmonella strains tested. The results demonstrate that $S$. enterica serotype Godesberg, $S$. Adelaide (one of two strains), $S$. Milwaukee, $S$. Niarembe, $S$. Bere and $S$. Arizonae (serogroup 63) have an atypical LPS core structure which is $R b_{1}$ type.
\end{abstract}

\section{Introduction}

The genus Salmonella has been differentiated into $>2400$ serotypes according to the Kauffmann-White Scheme [1]. This is based on the biochemical diversity of the flagellar and somatic antigens $(\mathrm{H}$ and $\mathrm{O}$ respectively). The $\mathrm{O}$ antigens are located on the lipopolysaccharide (LPS) molecules which project from the outer leaflet of the outer membrane of the gramnegative bacterial cell. LPS is divided into three regions - a hydrophobic lipid A residue linked to an oligosaccharide core region and a hydrophilic Opolysaccharide or O-chain (Fig. 1). The O-chain region is composed of repeating subunits of differing chain lengths. Polysaccharide chains with the same chain lengths co-migrate in SDS-PAGE gels to form a 'ladder' pattern [2]. The 3-D architecture and conformational flexibility of complete LPS molecule (Stype) has been predicted [3]. It is generally accepted that all Salmonella spp. have the same core structure, termed Ra type LPS [4] (Fig. 1). However, there have been a few reports proposing that non-Ra type core structures also occur [5-7].

Initial LPS core studies have used a monoclonal antibody (MAb) T6 [8] which binds to the Nacetylglucosamine $\rightarrow$ glucose portion of the salmonella Ra type LPS (Fig. 1). This antibody has been used for salmonella identification purposes $[9,10]$. MAb T6 did not react with $29 \%$ of the 96 serotypes belonging to

Received 10 April 2000; revised version accepted 12 Sept. 2000.

Corresponding author: Dr S.J. Forsythe (e-mail: stephen. forsythe@ntu.ac.uk). serogroups $F$ to 67 [5]. This indicated that a significant number of salmonellae may lack the Ra type core. However, this does not identify the structure of the non-Ra type core. The work reported here used the MAb M105 which binds to the three sugar residues of $\mathrm{N}$-acetylglucosamine $\rightarrow$ glucose $\rightarrow$ galactose in the outer core region of salmonella LPS (Fig. 1). It binds to $\mathrm{Ra}$ and less effectively to the $\mathrm{R} b_{1}$ and $R b_{2}$ regions of LPS [11].

Previous studies have used dot-blots to measure reactivities of antibodies with LPS [5]. However, when this method is used the LPS core region may be inaccessible because of the presence of the heterogeneous LPS chain lengths and other cellular material. In the present study, extracted LPS was separated according to chain length by SDS-PAGE before determining its reactivity with MAb M105.

\section{Materials and methods}

\section{Bacterial strains}

Rough mutant strains of $S$. enterica serotype Minnesota were provided by Professor I. Poxton (University of Edinburgh). One strain of $S$. Ealing was donated by Professor K. Nielsen (Animal Diseases Research Institute of Agriculture, Canada). S. Gallinarum was from Campden \& Chorleywood Food Research Association, UK. All other strains were from the culture collection at the Nottingham Trent University and Dynal Research and Development Laboratories (Dynal A/S, Norway). All cultures were maintained on tryptone soya agar (TSA) slopes and were grown 
a
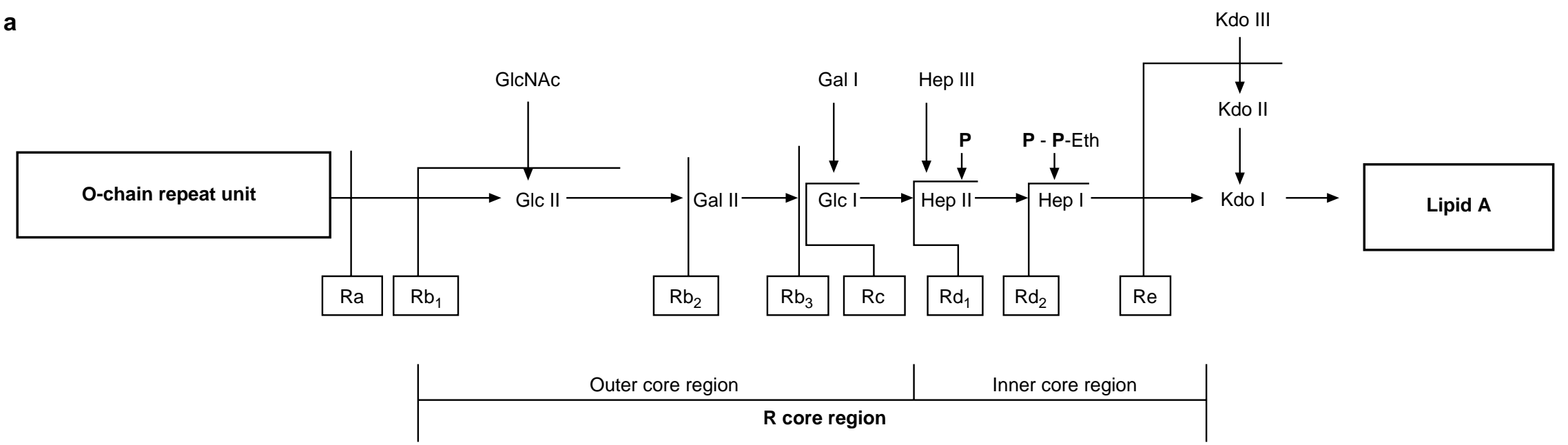

b

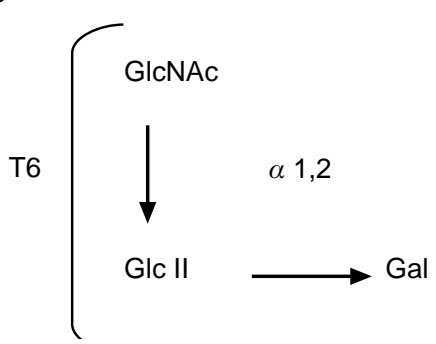

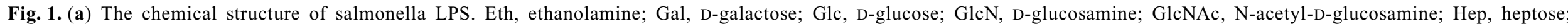
KDO, 3-deoxy-D-manno-octo-2-ulopyranosonic acid; P, phosphate. (b) Structure of MAb M105 binding site in the outer core region. Antibody T6 binding site is also indicated. 
overnight in $10 \mathrm{ml}$ of buffered peptone water (Oxoid) at $37^{\circ} \mathrm{C}$.

\section{LPS preparation and analysis by SDS-PAGE and immunoblotting}

Pure LPS was obtained from Sigma. Dr O. Holst (The Forschungs Zentrum, Germany) kindly donated the same purified LPS material as previously used with T6 [5]. Pure LPS was dissolved in distilled water $(1 \mathrm{mg} / \mathrm{ml})$ before analysis. LPS extracts from bacteria were prepared by proteinase $\mathrm{K}$ digestion of whole-cell lysates [12]. Procedures for SDS-PAGE and immunoblot analysis of LPS have been described previously [12].

\section{Immunology}

Protein A affinity-purified murine MAb M105 (from Professor K. Nielsen) was diluted in bovine serum albumin (BSA) $1 \%$ in Tris-buffered saline (TBS). MAb M105 was detected with an alkaline phosphataselabelled rabbit anti-mouse IgG 'secondary' antibody (Dako A/S, Denmark).

\section{Results}

\section{LPS banding profiles}

LPS was extracted from 42 strains by proteinase $\mathrm{K}$ digestion and by the phenol-water process, and analysed by SDS-PAGE. It was evident that the LPS profiles could be grouped according to the distribution of LPS chains (Fig. 2). In profile A, the LPS bands had
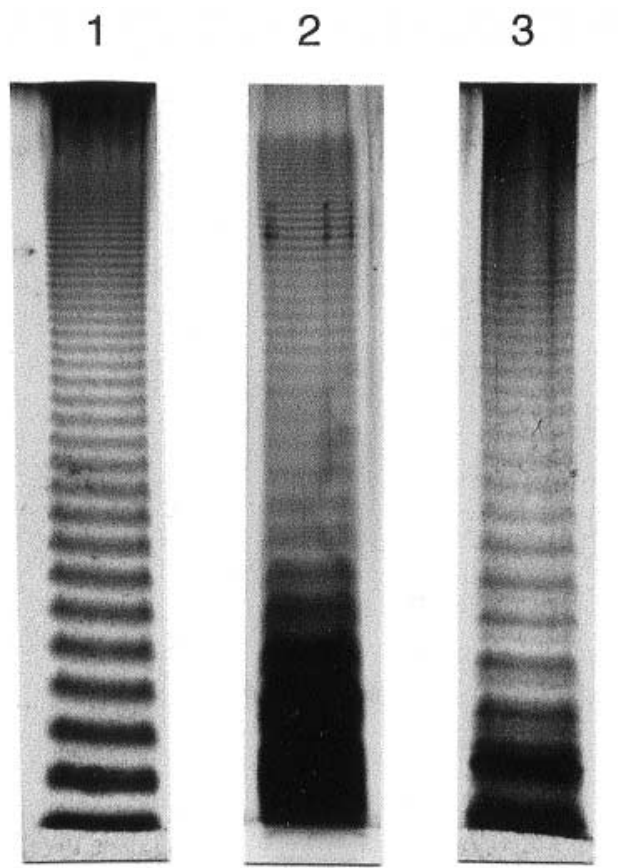

4

Fig. 2. SDS-PAGE profile types A-D of Salmonella LPS. Lane 1, $S$. Typhimurium (type A); 2, $S$. Agona (type B); 3, $S$. Newport (type C); 4, S. Arizonae (type D). This figure is a composite photograph from different gels. equal intensity from short to long chains. Profile B had predominantly short and medium size chains, which resulted in more intense bands in the lower half of the gel. In profile $\mathrm{C}$, there was a concentration of very short chains; medium and long chains were also present. Profile D had predominantly short and long chains. Six strains had profile A, 10 strains profile B, 12 strains profile $\mathrm{C}$ and 14 strains had profile D (Table $1)$.

\section{Immunoblot assays}

Purified LPS from rough mutant strains of $S$. Typhimurium ( $\mathrm{Ra}, \mathrm{Rb}_{1}, \mathrm{Rc}$ and $\mathrm{Re}$ ) and $S$. Minnesota (Ra, $\mathrm{Rb}_{2}, \mathrm{Rc}, \mathrm{Rd}_{1}, \mathrm{Rd}_{2}$ and $\mathrm{Re}$ ) were analysed by immunoblot assays with MAb M105. MAb M105 reacted with $R a$ and $R b_{1}$ type LPS and failed to react with LPS from $\mathrm{Rb}_{2}, \mathrm{Rc}, \mathrm{Rd}_{1}, \mathrm{Rd}_{2}$ and $\mathrm{Re}$ mutant strains of Salmonella.

\section{Immunoblot binding profiles}

As described previously [12], the MAb M105 immunoblot reaction with salmonella LPS resulted in one of three reactions (Fig. 3). In type 1, the MAb reacted with all LPS molecules regardless of O-chain length. In type 2, the MAb reacted strongly with R-type LPS and weakly with SR-type LPS and short-chain LPS. This weak reaction was often seen as a smear rather than a band. In type 3, the MAb reacted weakly with R-type LPS. Table 2 summarises the immunoblot reactions of all Salmonella strains tested. All serotypes belonging to serogroups $\mathrm{B}, \mathrm{C}_{2}, \mathrm{C}_{3}, \mathrm{D}$ and $\mathrm{E}$ gave reaction type 1 . Salmonellae of serogroups $\mathrm{C}_{1}, \mathrm{~F}$ and $\mathrm{L}$ reacted with short-chain and R-type LPS only (reaction type 2), whereas strains belonging to serogroups $\mathrm{G}, \mathrm{K}, \mathrm{O}, \mathrm{U}, \mathrm{V}$, $\mathrm{X}$ and 63 expressed the third reaction type. Strains of the same serogroup in some cases produced different reactions. For example, MAb M105 bound with the Rtype LPS only of $S$. Godesberg strain 1140, whereas it bound with SR- and R-type LPS from strain 1431. The antibody reacted with R-type LPS of $S$. Arizonae serogroup 63 (strain 10463) and not with strain 1803 (serogroup 51). Moreover the M105 antibody did not react with $S$. Djakarta (serogroup Y) LPS. The M105 antibody did not react with the LPS profiles of any of the non-salmonella Enterobacteriaceae analysed.

\section{Discussion}

SDS-PAGE and immunoblot assay techniques were used to study the binding of MAb M105 with LPS from various strains of Salmonella belonging to different serogroups and also rough mutants. MAb M105 bound strongly to LPS prepared from rough mutant Ra strains of $S$. Typhimurium and $S$. Minnesota. The antibody bound to a lesser degree to $\mathrm{Rb}_{1}$ rough $S$. Typhimurium mutant strain. MAb M105 failed to bind to LPS from $\mathrm{Rb}_{2}, \mathrm{Rc}, \mathrm{Rd}_{1}, \mathrm{Rd}_{2}$, Re mutant $S$. 
Table 1. LPS profiles of Salmonella strains

\begin{tabular}{|c|c|c|c|c|c|}
\hline Serogroup & Serotype (strain) & Profile & Serogroup & Serotype (strain) & Profile \\
\hline \multirow[t]{9}{*}{ B } & S. Abortusequi (L-5886) & $\mathrm{D}$ & $\mathrm{E}_{4}$ & S. Senftenberg & $\mathrm{B}$ \\
\hline & S. Agona & $\mathrm{B}$ & $\mathrm{F}$ & S. Arizonae (1823) IIIa & $\mathrm{D}$ \\
\hline & $S$. Bredeney & B & & $S$. Arizonae (10455) IIIb & $\mathrm{D}$ \\
\hline & $S$. Gallinarum & $\mathrm{C}$ & G & $S$. Arizonae (10466) IIIa & $\mathrm{D}$ \\
\hline & S. Saintpaul & B & $\mathrm{K}$ & S. Cerro $(10390)$ & A \\
\hline & $S$. Typhimurium & $\mathrm{A}$ & $\mathrm{L}$ & S. Minnesota & $\mathrm{D}$ \\
\hline & $S$. Typhimurium (L-6511) & A & & S. Minnesota (L-6261) & $\mathrm{D}$ \\
\hline & $S$. Typhimurium (1135) & A & $\mathrm{N}$ & $S$. Godesberg (1140) & $\mathrm{C}$ \\
\hline & S. Typhimurium (1835) & A & & S. Godesberg (1431) & $\mathrm{C}$ \\
\hline \multirow[t]{3}{*}{$\mathrm{C}_{1}$} & $S$. Infantis & $\mathrm{D}$ & $\mathrm{O}$ & S. Adelaide & B \\
\hline & $S$. Livingstone & $\mathrm{D}$ & & S. Adelaide (1464) & $\mathrm{B}$ \\
\hline & S. Virchow & $\mathrm{D}$ & & $S$. Ealing & B \\
\hline \multirow[t]{3}{*}{$\mathrm{C}_{2}$} & $S$. Hadar & A & & $S$. Ealing (Canada) & $\mathrm{B}$ \\
\hline & S. Manchester & $\mathrm{C}$ & $\mathrm{U}$ & S. Milwaukee (1139) & B \\
\hline & $S$. Newport & $\mathrm{C}$ & $\mathrm{V}$ & $S$. Niarembe (1660) & $\mathrm{C}$ \\
\hline $\mathrm{C}_{3}$ & S. Kentucky & $\mathrm{C}$ & $\mathrm{X}$ & $S$. Bere (10392) & $\mathrm{D}$ \\
\hline \multirow[t]{4}{*}{$\mathrm{D}_{1}$} & S. Dublin & $\mathrm{C}$ & & S. Bere (10403) & $\mathrm{D}$ \\
\hline & $S$. Enteritidis & $\mathrm{C}$ & $\mathrm{Y}$ & S. Djakarta & $\mathrm{C}$ \\
\hline & S. Enteritidis (L-6011) & $\mathrm{B}$ & 51 & S. Arizonae & $\mathrm{D}$ \\
\hline & S. Panama & $\mathrm{D}$ & & S. Arizonae (1803) IIIa & $\mathrm{C}$ \\
\hline $\mathrm{E}_{4}$ & S. Give & $\mathrm{C}$ & 63 & S. Arizonae (10463) IIIb & $\mathrm{D}$ \\
\hline
\end{tabular}

1

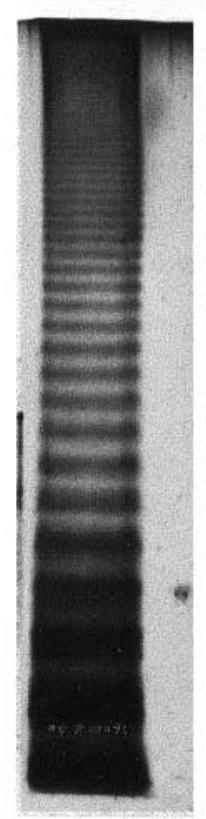

2

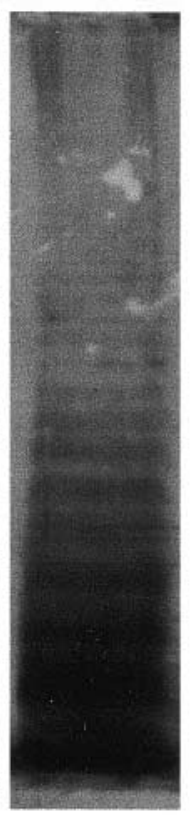

3

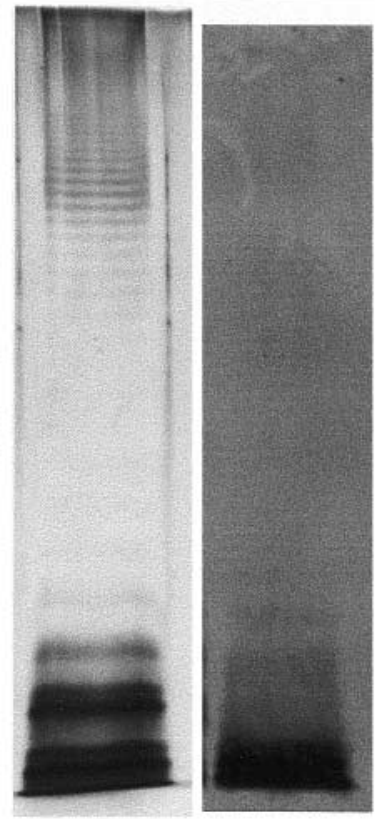

5

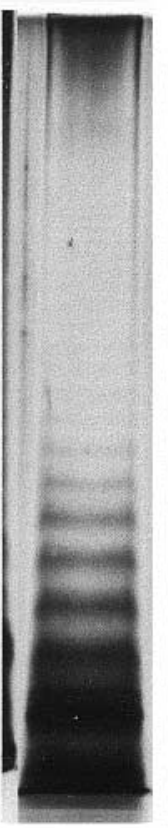

6

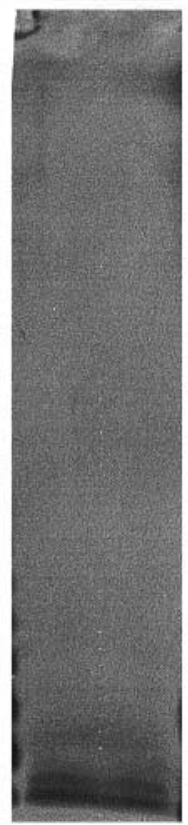

Fig. 3. SDS-PAGE (lanes 1, 3, 5) and immunoblots (lanes 2, 4, 6) of Salmonella LPS with the MAb M105. Lanes 1 and 2, $S$. Manchester (reaction type 1); 3 and 4, S. Infantis (reaction type 2); 5 and 6, S. Adelaide (reaction type 3). This figure is a composite photograph from different gels.

Typhimurium and $S$. Minnesota strains. This confirmed the epitope site for M105 as shown in Fig. 1.

In reaction type 1 , MAb M105 bound to all bands in the LPS profile and demonstrated that the M105 epitope was present and accessible. Reaction type 1 was obtained with Salmonella strains from serogroups $\mathrm{B}, \mathrm{C}_{2}, \mathrm{C}_{3}, \mathrm{D}$ and $\mathrm{E}$ (Table 2). In reaction type $2, \mathrm{MAb}$ M105 bound to LPS molecules with short O-chain length and R-type LPS only (Table 2). The restricted binding of serogroup $\mathrm{C}_{1}, \mathrm{~F}$ and $\mathrm{L}$ salmonellae could be explained by steric hindrance to the epitope recognised by MAb M105, caused by the addition of a few or more O-chain units. Although they share common Oantigen $\mathrm{O}: 6$, the O-chains of subgroups $\mathrm{C}_{2}$ and $\mathrm{C}_{3}$ (reaction type 1) and $\mathrm{C}_{1}$ (reaction type 2) are composed of different sugars. For example, the Ochains of Salmonella subgroups $\mathrm{C}_{2}$ and $\mathrm{C}_{3}$ have main chains composed of tetrasaccharide repeating units and two lateral monosaccharide substituents (abequose and glucose), whereas the O-chains of Salmonella subgroup $\mathrm{C}_{1}$ have a main chain with pentasaccharide repeating 
Table 2. Reactivities of a range of Salmonella strains with M105 and T6 antibodies in immunoblot assays

\begin{tabular}{|c|c|c|c|c|c|}
\hline Serogroup & Serotype (strain) & $\begin{array}{c}\text { MAb M105 } \\
\text { immunoblot } \\
\text { reaction type* }\end{array}$ & Serogroup & Serotype (strain) & $\begin{array}{l}\text { MAb M105 } \\
\text { immunoblot } \\
\text { reaction type }\end{array}$ \\
\hline \multirow[t]{9}{*}{ B } & S. Abortusequi (L-5886) & 1 & $\mathrm{E}_{4}$ & S. Senftenberg & 1 \\
\hline & S. Agona & 1 & $\mathrm{~F}$ & $S$. Arizonae (1823) IIIa & $2(+)^{\dagger}$ \\
\hline & $S$. Bredeney & 1 & & S. Arizonae (10455) IIIb & 2 \\
\hline & S. Gallinarum & 1 & G & S. Arizonae (10466) IIIa & 3 \\
\hline & S. Saintpaul & 1 & $\mathrm{~K}$ & $S$. Cerro $(10390)$ & $3(+)$ \\
\hline & $S$. Typhimurium & 1 & $\mathrm{~L}$ & S. Minnesota & 2 \\
\hline & $S$. Typhimurium (L-6511) & 1 & & S. Minnesota (L-6261) & 2 \\
\hline & $S$. Typhimurium (1135) & 1 & $\mathrm{~N}$ & $S$. Godesberg (1140) & $3(+)$ \\
\hline & S. Typhimurium (1835) & 1 & & S. Godesberg (1431) & $2(+)$ \\
\hline \multirow[t]{3}{*}{$\mathrm{C}_{1}$} & $S$. Infantis & 2 & $\mathrm{O}$ & S. Adelaide & 3 \\
\hline & $S$. Livingstone & 2 & & $S$. Adelaide (1464) & $3(-)$ \\
\hline & $S$. Virchow & 2 & & $S$. Ealing & 3 \\
\hline \multirow[t]{3}{*}{$\mathrm{C}_{2}$} & $S$. Hadar & 1 & & S. Ealing (Canada) & 3 \\
\hline & S. Manchestes & 1 & $\mathrm{U}$ & S. Milwaukee (1139) & $3(-)$ \\
\hline & $S$. Newport & 1 & $\mathrm{~V}$ & $S$. Niarembe $(1660)$ & $3(-)$ \\
\hline $\mathrm{C}_{3}$ & S. Kentucky & 1 & $\mathrm{X}$ & $S$. Bere (10392) & $3(-)$ \\
\hline \multirow[t]{4}{*}{$\mathrm{D}_{1}$} & $S$. Dublin & 1 & & S. Bere (10403) & $3(-)$ \\
\hline & $S$. Enteritidis & 1 & $\mathrm{Y}$ & S. Djakarta & No reaction $(-)$ \\
\hline & S. Enteritidis (L-6011) & 1 & 51 & S. Arizonae & 3 \\
\hline & S. Panama & 1 & & S. Arizonae (1803) IIIa & No reaction $(-)$ \\
\hline $\mathrm{E}_{4}$ & S. Give & 1 & 63 & S. Arizonae (10463) IIIb & $3(-)$ \\
\hline
\end{tabular}

* Reaction types are explained in the text.

${ }^{\dagger}$ Results with T6 antibody are given in parentheses.

units and side chains [13]. Hence, differences in the reactivities of the subgroups $\mathrm{C}_{2}$ and $\mathrm{C}_{3}$ could also be explained by differences in the 3-D architecture and rigidity of their O-chains [3].

The immunoblots of Salmonella strains from serogroups $\mathrm{G}, \mathrm{K}, \mathrm{O}, \mathrm{U}, \mathrm{X}$ and 63 revealed that MAb M105 bound to R-type LPS with reduced reactivity (reaction type 3). Failure of MAb M105 to bind to SR-type and S-type LPS suggested that the epitope became unavailable in the presence of one O-chain repeat unit [14].

The antibody T6 is specific for the outer core region of Ra-type LPS [8] and, unlike MAb M105, it does not bind to $\mathrm{Rb}_{1}$-type LPS (Fig. 1b). The T6 antibody specificity is not only defined by the presence of the Nacetyl glucosamine (GlcNAc) residue, but also the bonding to the core oligosaccharide [8]. As all strains in this study bound MAb M105, their LPS core structures were taken to be $\mathrm{Ra}$ or $\mathrm{Rb}_{1}$ type. The $\mathrm{T} 6$ antibody has confirmed the presence of typical Ra-type LPS core structures in many Salmonella serotypes from serogroups A, B, C, D and E $[5,8,15,16]$. Subsequently, it was predictable that MAb M105 would bind to these serogroups (Table 2). In contrast, a large proportion of the Salmonella strains from other serogroups analysed lacked the T6 epitope $[8,16,17]$. Many of these samples were the same LPS material as previously used [5]. The R-type LPS from Salmonella strains which reacted with MAb M105 were previously reported not to bind T6 antibody [5] (Table 2). Hence they probably contain atypical $\mathrm{Rb}_{1}$-type core LPS. These included $S$. Adelaide (1464, serogroup O), $S$. Milwaukee (serogroup U), S. Niarembe (1660, sero- group V), S. Arizonae (10463, serogroup 63) and both strains of $S$. Godesberg (serogroup N) and $S$. Bere (serogroup X). The S-, SR- and R-type LPS of $S$. Djakarta (serogroup Y) and $S$. Arizonae (1803; serogroup 51) failed to react with T6 and M105 antibodies. Based on the known specificities of these antibodies (Fig 1b), it can be concluded that the core LPS of $S$. Djakarta (10403) and $S$. Arizonae (1803) did not contain $\mathrm{Ra}-$ or $\mathrm{Rb}_{1}$-type core structures.

Chemical analysis of LPS composition and structure requires considerable expertise and facilities [7]. However, immunological studies of LPS are less demanding and, therefore, could be used as an initial screening method before chemical analysis. The present study has confirmed that MAb M105 bound to a wider range of salmonellae than the T6 antibody. Thus, these results provided immunological evidence that $\mathrm{Rb}_{1}$ and other atypical core structures exist in the R-type LPS of certain wild-type Salmonella strains.

\section{References}

1. Edwards PR, Ewing WH. Identification of Enterobacteriaceae, 3rd edn. Minneapolis, MN, Burgess. 1972.

2. Tsai C-M, Frasch CE. A sensitive silver stain for detecting lipopolysaccharides inpolyacrylamide gels. Anal Biochem 1982; 119: $115-119$.

3. Kastowsky M, Gutberlet T, Bradaczek H. Molecular modelling of the three-dimensional structure and conformational flexibility of bacterial lipopolysaccharide. J Bacteriol 1992; 174: 4798-4806.

4. Kato N. Crystallization and electron microscopy of bacterial lipopolysaccharide (LPS). Micron 1993; 24: 91-114.

5. Tsang RSW, Schlecht S, Aleksíc S, Chan KH, Chau PY. Lack of the $\alpha$-1,2-linked N-acetyl-D-glucosamine epitope in the outer core structures of lipopolysaccharides from certain $\mathrm{O}$ serogroups and subspecies of Salmonella enterica. Res 
Microbiol 1991; 142: 521-533.

6. Tsang RSW, Schlecht S, Mayer H. Structural differences in the outer core region of lipopolysaccharides derived from members of the genus Salmonella. Zentralbl Backteriol 1992; 276: $330-339$.

7. Olsthoorn MMA, Petersen BO, Schlecht S et al. Identification of a novel core type in salmonella lipopolysaccharide. $J$ Biol Chem 1998; 273: 3817-3829.

8. Tsang RSW, Chan $\mathrm{KH}$, Chau PY, Wan $\mathrm{KC}, \mathrm{Ng} \mathrm{MH}$, Schlecht S. A murine monoclonal antibody specific for the outer core oligosaccharide of Salmonella lipopolysaccharide. Infect Immun 1987; 55: 211-216.

9. Tsang RSW, Nielson KH, Henning DM et al. Screening for Salmonella with a murine monoclonal antibody M105 detects both Felix O1 bacteriophage sensitive and resistant Salmonella strains. Zentralbl Bakteriol 1997; 286: 23-32.

10. Mansfield LP, Forsythe SJ. Detection of salmonellae in foods. Rev Med Microbiol 2000; 11: 37-46.

11. Tsang RSW, Nielsen K, Henning MD, Schlecht S, Aleksíc S. A murine monoclonal antibody that recognises a genus-specific epitope in the Salmonella lipopolysaccharide outer core. Zentralbl Bakteriol 1991; 274: 446-455
12. Mansfield LP, Billett EE, Olsen E, Forsythe SJ Variation in Salmonella core lipopolysaccharide as detected by the monoclonal antibody M105. Lett Appl Microbiol 1996; 23: 104-106.

13. Knirel YA, Kochetkov NK. [Structure of lipopolysaccharides of gram-negative bacteria III. Structure of O-specific polysaccharides.] Biokhimiia 1994; 59: 1784-1851.

14. Nelson JW, Barclay GR, Micklem LR, Poxton IR, Govan JRW. Production and characterisation of mouse monoclonal antibodies reactive with the lipopolysaccharide core of Pseudomonas aeruginosa. J Med Microbiol 1992; 36: 358-365.

15. Choi D, Tsang RSW, Ng MH. Sandwich capture ELISA by a murine monoclonal antibody against a genus-specific LPS epitope for the detection of different common serotypes of salmonellas. J Appl Bacteriol 1992; 72: 134-138.

16. Ng SP, Tsui CO, Roberts D, Chau PY, Ng MH. Detection and serogroup differentiation of Salmonella spp. in food within 30 hours by enrichment-immunoassay with a T6 monoclonal antibody capture enzyme-linked immunosorbent assay. Appl Environ Microbiol 1996; 62: 2294-2302.

17. Tsang RSW, Schlecht S. Smooth lipopolysaccharide of Salmonella adelaide has an atypical Salmonella Ra core. Res Microbiol 1990; 141: 671-678. 